\title{
Craving nicotine: It's in the genes
}

Q uitting smoking is perceived as a struggle of mind over matter, but nicotine dependence seems to be determined in part by one's genes. It is known that nicotine interacts with nicotinic acetylcholine receptors (nAChRs) in the brain, although how this interaction leads to a chemical dependence remains unclear. However, new research identifies a specific area of one $\mathrm{nAChR}$ as a prime target in the development of nicotine dependence.

Tapper and colleagues, in a recent article in Science, ${ }^{1}$ report that a mutation in the $\alpha 4$ nAChR subunit lowers the threshold of nicotine dependence in mice. Their research takes us another step closer toward understanding the genetics underlying an addiction that contributes to over 4 million deaths worldwide each year.

\section{Nicotine and nAChRs}

The brain is known to be affected both negatively and positively by nicotine, which acts to induce addiction and increase mental alertness. Over the years, both effects have been linked to nAChRs present on neurons in the central nervous system. These receptors form a family of ion channels normally activated by the neurotransmitter acetylcholine, although they also bind nicotine.

At the molecular level, nAChRs are extremely well characterized. Each receptor channel is composed of 5 components assembled from a pool of 12 known subunits. These

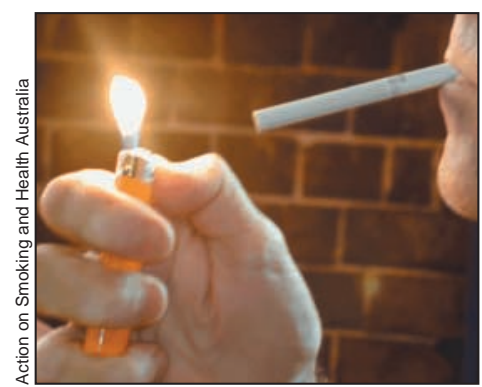

combinations produce a variety of receptor subtypes, each with distinctive properties. This complexity has left many unanswered questions concerning nAChRs in vivo, in particular how different subtypes contribute to nicotine addiction.

Mouse models are providing some clues. In 1998, Picciotto and colleagues, at the Institut Pasteur, revealed that mice lacking the $\beta 2 \mathrm{nAChR}$ subunit failed to self-administer nicotine after having done so with cocaine. ${ }^{2} \mathrm{~A}$ second study revealed that mice without the $\beta 2$ and $\alpha 4$ subunits did not release dopamine on nicotine exposure, a response thought to be involved in the development of addiction. ${ }^{3}$ Results of both studies implicate the $\alpha 4$ and $\beta 2 \mathrm{nAChR}$ subunits in the formation of nicotine dependence.

\section{To what extent does genetics underlie addiction?}

Although these previous studies provided evidence that the $\alpha 4$ and $\beta 2 \mathrm{nAChR}$ subunits are necessary for the formation of nicotine dependence, they did not address the question of whether only these subunits are required. Tapper and colleagues focused on this question, reasoning that an $\alpha 4$ subunit hypersensitive to nicotine might provide the answer.

Such a subunit was engineered by making a single point mutation that allowed the molecule to be activated by nicotine concentrations as low as $10 \mathrm{nM}$ (a level that fails to activate other nAChR subtypes). This mutant subunit, termed $\alpha 4^{*}$, was then used to replace the normal mouse copy of $\alpha 4$, thereby creating a "knock-in" mouse line hypersensitive to nicotine.

Both the homozygous and heterozygous mice carrying $\alpha 4^{*}$ were viable, fertile and showed no gross developmental abnormalities, although they ex-

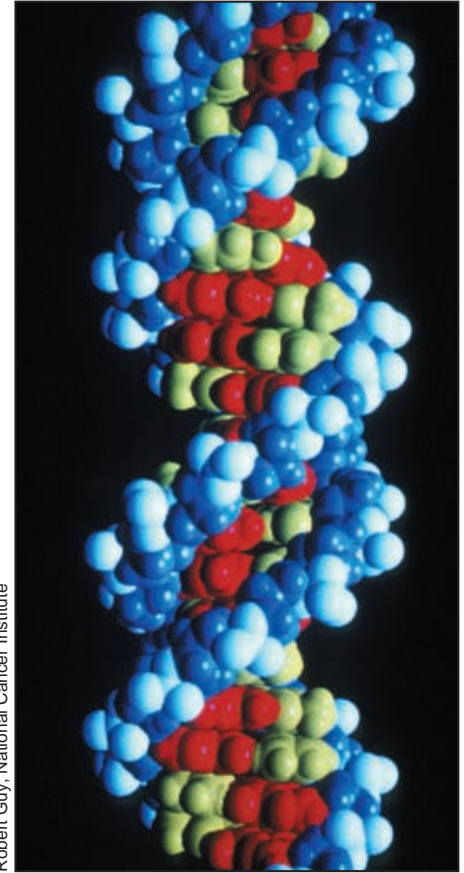

pressed slightly lower levels of $\alpha 4$ and $\beta 2$ receptors. Nonetheless, $\alpha 4^{*}$ mice responded to levels of nicotine roughly 50 times lower than levels found in smokers' blood.

Tapper and colleagues then tested the behavioural responses of $\alpha 4^{*}$ mice to acute and chronic doses of nicotine. For instance, wild-type mice will show nicotine-induced reinforcement when given the choice between a chamber where they can selfadminister nicotine and a chamber where they can't, spending significantly more time overall in the presence of nicotine. Tapper and colleagues found that $\alpha 4^{*}$ mice could be similarly conditioned at a level of nicotine roughly 50 times lower, an amount at which wild-type mice did not show a preference. ${ }^{1}$ This result suggests that $\alpha 4^{*}$ is sufficient for the reinforcing effects of nicotine.

An alternative to nicotineinduced reinforcement is tolerance, which is thought to be necessary for the development and, perhaps more importantly, maintenance of dependence. Tolerance is characterized in mice by the absence of nicotine- 
induced hypothermia on chronic nicotine infusion. The $\alpha 4^{*}$ mice were found to acquire a tolerance within 8 days at a dose of nicotine that produced little effect in wild-type mice.

Thus, Tapper and colleagues neatly revealed that $\alpha 4^{*}$ receptors are sufficient for the production of 2 essential aspects of nicotine addiction - reinforcement and tolerance. Perhaps the most intriguing aspect of this work is how it might alter our understanding of addiction. The $\alpha 4$ and $\beta 2$ subunits are known to be mutated in the human population, and such mutations are also known to affect nAChR function. Thus, as Hogg and Bertrand muse, ${ }^{4}$ in an article accompanying the report by Tapper and colleagues, it must be wondered whether $\alpha 4$ and $\beta 2$ subunit mutations in the human population are associated with addictive behaviour. A positive answer might suggest that quitting smoking will be harder if your genes are stacked against you. ${ }^{1,4}$ — David Secko, Vancouver

\section{References}

1. Tapper AR, McKinney SL, Nashmi R, Schwarz J, Deshpande P, Labarca C, et al. Nicotine activation of $\alpha 4^{*}$ receptors: sufficient for reward, tolerance, and sensitization. Science 2004;306:1029-32.

2. Picciotto MR, Zoli M, Rimondini R, Lena C, Marubio LM, Pich EM, et al. Acetylcholine receptors containing the $\beta 2$ subunit are involved in the reinforcing properties of nicotine. $\mathrm{Na}$ ture 1998;391:173-7.

3. Marubio LM, Gardier AM, Durier S David D, Klink R, Arroyo-Jimenez $M M$, et al. Effects of nicotine in the dopaminergic system of mice lacking the $\alpha 4$ subunit of neuronal nicotinic acetylcholine receptors. Eur 7 Neurosci 2003;17:1329-37.

4. Hogg RC, Bertrand D. Neuroscience. What genes tell us about nicotine addiction. Science 2004;306:983-5.

\section{CMAJ.JAMCél}

CMAJ is powered by HighWire Press — the world leader in online journal publishing.

Search all of MEDLINE and access more than 340 highly cited journals, including CMAJ, the New England Journal of Medicine, JAMA and BMJ.

CMAJ features:

search by author, keyword, title or citation

customized alerts on the topics of particular interest to you

email table of contents service

search all of MEDLINE

rapid submission of letters to the editor

subject collections for easy browsing

email a friend

instant notification of articles released early

\section{cmaj.ca}

